Southampton, and the Ryde and Sconce Point plates by a
wire through Newport; the circuit was completed by the wire through Newport; the circuit was completed by the
sea, and signals were passed easily so as to read by the Morse system, but speech was not practical with the telepbone." without Wires," read by Mr. J. B. Lindsay to the Mathema-
tical Section of the British Association, at its meeting in tical Section of the British Association, at its meeting in
Aberdeen, in September, 1859, which appeared in the Dundee proceeded to describe bis process, saying:

"Recently be had made additional experiments, and succeeded in crossing the Tay where it was three-quarters of a mile broad. His method had always been to immerse two hy a wire passing through a coil to move a needle, and to
have on the other side two sheets similarly connected, and nearly opposite the two former. Experiments had shown across, and that the quantity that thus goes across can be increased in four ways: First, hy an increased battery power third, by increasing the coil that moves the receiving needle and fourth, by increasing the lateral distance. In cases ing it, as by that means a smaller battery was requisite. In telegraphing by this method to Ireland or France, abundance distance in Britain was much less than the distance across. had been double the distance across; but in the experiments
in the Tay the lateral distance was the smaller, being only about balf a mile, while the distance across was three-quarthought that if any one were doubled the quantity of elec-
tricity that crossed would also be doubled; and if all the
elements were doubled the quan tity transmitted would be elements were doubled the quantity transmitted would he
eight times as great. In the experiment across the Tay the
battery battery was of four square feet of zinc, the immersed sheets
contained about ninety square feet, the weight of the copper contained about ninety square feet, the weight of the copper the transverse distance, but if it bad been a mile, and the distance across also a mile, the signal would no doubt bave
becn equally distinct. Should the above law (when the lateral distance is equal to the transverse) be fou
undernentioned table might then be formed.

"But supposing the lateral distance to be only balf the transverse, then the distance crossed might be 16,000 miles, Further experiments were, however, necessary to determine the law. Since last experiment be bad increased the coil,
and thought there was power to come two miles. Accordin to this calculation, be thought a battery of 130 square feet immersed sheets of 3,000 square feet, a coil of 210 pounds
weight were sufficient to cross the Atlantic with the latera distance that could be obtained in Great Britain
The following is the table above referred to:

\begin{tabular}{|c|c|c|c|}
\hline $\begin{array}{l}\text { Zinc for } \\
\text { Battery. }\end{array}$ & $\begin{array}{l}\text { Immersed } \\
\text { Sheete. }\end{array}$ & Coil. & $\begin{array}{l}\text { Distance } \\
\text { Crossed. }\end{array}$ \\
\hline$\frac{4}{8}$ sq. ft. & 90 sq. ft. & 61 & 1 mile. \\
\hline$"$ & “، & $\begin{array}{l}12 \\
24\end{array}$ & 64 \\
\hline “ & 720 & $48 \cdots$ & $512 “$ \\
\hline 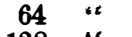 & 1,440 & 96 “ & 4,096 "s \\
\hline$"$ & 2,880 & 192 & 32,768 \\
\hline
\end{tabular}

If Mr. Lindsay's bopes are to be realized, some great dis covery yet remains to be made, for, by the laying of the At lantic telegraph cables, we know that the electric current
transmitted across the wide expanse of the Atlantic, must be of extraordinary power to be apparent on the other side, even
with a cable to lead it. Without a cable it would be hopeless to expect to find it, although the best apparatus were
employed. Telegraphic instruments are grestly improved teries and coils be would find available for bis purpose all that be could wish. No currents, bowever, are in use which
would induce another current 2,000 or 3,000 miles away. Still it is within possibility that such may be found, and to Dundonian must be ascribed the honor of baving first con-
ceived the scheme of transoceanic telegraph communication ceived the scheme of tran
without the aid of cables.

\section{ON ELECTRIC METERS.*}

\section{By C. Vernon Boys}

Mr. Bors exhibited an extensive series of models bearing on the subject of power-measuring in general, which might
be applied to electrical measurement in particular. The
general principle was applicable to differential metronomy, general principle was applicable to differential metronomy, and all the apparatus were based on the same idea,though the of potential was in one or two of the instruments exceed-
ingly complicated. The fundamental idea utilized in the mechanism consisted in a wheel rotating in contact with a
cylinder, but at an angle of about 30 degrees with the perpendicular cross. section of the latter. The result was a tudinal motion of the cylinder, if the cylinder was left free to move endwise. By a clockwork arrangement the wheel
motion, when the cylinder had reached the end of its path, was transformed into a motion in the contrary direction, and thus the cylinder was forced to turn continuously within its cations of this mechanical principle, which Mr. Boys described as comparatively novel, were described as numer-
ous and of wide range. One instrument adapted as a dif ous and of wide range. One instrument adapted as a dif
ferential electric meter was spoken of by Sir William Thom son as novel and highly ingenious. T"be apparatus consist ed of two small magnetized steel cones, revolving on sepa-
rate spindles, point downward, so that each spindle might be connected with a separate source of power. A small ing each of them with one end, and retained in position
merely by the fact of the cones acting as magnets. When revolution was set up in the cones, the inventor showed that the cross iron remaned always paralle to its original posi-
tion if the two velocities were equal; but immediately that
either of the cones moved more rapidly than the other, it was demonstrated that the angular displacement of the iron
indicated with absolute accuracy the differential velocity of the spindles. Sir William Thomson, in remarking on the
ingenuity displayed, stated that the latter instrument might be a valuable application in the measurement of potentia differences hetween two electrical currents.
THE THICKNESS OF WIRE NECESSARY TO CARRY
DIFFERENT ELECTRIC CURRENTS WITHOUT OVERHEATING.

By Prof. G. Forbes.

ONE would expect that if one wire would carry a current of one volt, then two similar wires would carry two volts.
This is so if the currents are very far apart, but when the the surface from which radiation is continually taking place Consequently, however likely it would seem at frst sight that me current carried would be proportional to the section, as
mater of fact it is not so. I find by experiment that if there is
departure from the law of the square of the diamer, the law is that the current is almost proportional to the diam ther of the wire. If y you can carry a definite amount of current
through a wire of a millimeter of thickness without beating it over a temperature of $150^{\circ}$, then if you want to carry
current twice as great through a wire you must bave one current twice as great through a wire you must bave one of
two millimeters dianeter-i. $e$, four times the section. Thi s a very serious matter in regard to the extension of electric
lighting. The method of arriving at the law was by taking pieces of wire of different diameters, putting a trace of beeswax upon them, and then hy diminishing the resistance
slowly so as to heat very gradually indeed, find the current necessary to melt the wax. Auother very importan aw which is necessary for us to know in order to
be able to change the type of dynamo so as to produce
another which will give any desired electromotive force, is bat when the wire is wound in coils so that the coils ar the same size, then the strength of the current which is
allowable is proportional to the square of the diame ter of the wire- $i$ e., to the section. In determiuing this law I used
small coils in tubes closed at one end, and filled with water of a definite temperature, then the current was raised read off-this law being the result.

\section{RECENT PROGRESS IN TELEPHONY.*}

By Willifam Henry Preece, F.R.S.

THE telephone was first introduced to the British public Glasgow, Sir Winliam Thomson starled all his bearers by Shakespeare quoted through an electric wire, hy the aid of nounced to be "the greatest by far of all the marvels of the electric telegraph." In 1877, at Plymouth, I bad the plea. instrument now known as the Bell Telephone, which I bad just brought uver from America, and conversation was Years bave elapsed since then, and it is fitting that the
British Association should bear of the progress made in the application of this astonishing apparatus. a practical instrument. $\$ 1,550,000$ capital is already eme-
barked in its extension in England, and it is earning a revenue of $£ 109,000$. Hitherto it bas been practically monopoly in the bands of a private company, who hold the
controlling patents, and of the Post-office, who possess the coutrolling power, hut owing to the policy of the present fresh patents bave come into existence, and we are about to witness severe competition. It is often said that competi-
tion in any husiness will bave the effect of reducing the rates charged to the public, but the experience of the past
in railways and telegraphs scarcely teaches this lesson; competition tends to lower the rates for a time, but it eventually leads to amalgamation, to the absorption of the
weak by the strong, to swollen and watered capital, aud public. in many instances, to bigher rates to a too-confiding The free traffic in patents, bowever, leads to jobbery and
The The free traffic in patents, bowever, leads to jobbery and
speculation of the worst type. We bave recently seen mania for electric speculations that almost rivals the South
Sea Bubble period. The public bave wildly rushed into illmatured schemes that bave swollen the purses of gambling provoters, bave turned the beads of inventors, bave re-
tarded the true progress of the beneficial application of this new science to the wants of man, and bave thrown away millions upon imperfect schemes. Much bas been said
against the monopoly of the Post-office in telegraphic busithe rapacity of company promoters and patent-mongers in that branch of the practical application of electricity, while
no one can assert that it bas checked the progress of teleraphy. During the first week that the telegraphs in this (the State, the total number of nessages transmitted was 26,000, while in the week ending
August 11, it amounted to 724,000 . There is no inventor who can assert that his scheme bas not received prope
consideration, nor show a real improvement that bas no been adopted and remunerated; while the improvements of and America itself, the bome of the inventor, bas found the Receivers.-The original telephone receiver of Bell bas scarcely been improved upon; it remains in torm and con-
straction very nearly the sane as that which I exhibited in
1877. The perfection of its working depends upon the truth and perfection of its manufacture. It is now more solid and substantial thau it was at first, more powerful magnets

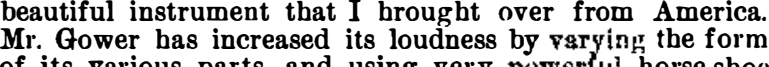
of its various parts, and using very powerlul horse shoe of its various parts, and using very powertul horse shoe
magnets of peculiar form; but experience sliows that loud-
ness is always obtained at the expense of clearness of articu. ness is always obtained at the expense of clearness of articuinstrument, which is adopted by the post-offices, and is now
in use to connect together all the sections of the British in use to connect together all the sections of the British the original Bell.
The Paris Exhibition of last year, so fruitful in electrica ovelties did Exhibition of last year, so fruitful in electrical telephonic apparatus. It was noticeable chiefly for its
practical applications of the telephone, and particularly to the transmission of singing and music to a distance. M sally used in Paris. It is a very bandy, pretty, and con- venient form. He utilizes a principle which be calls " surex ear-piece and the diapbra cmon and this is said to increase the vibrating iron diaphragm. A simple experimental apparatus
of $\mathrm{M}$. Ader's shows that there is some foundation for this fact: when a thin steel spring is adjusted close to the poles proach of a mass of iron to the spring will cause it to be D'A hy the magnet.

D'Arsonval has also modified the Bell receiver. He bas
placed the coil in a powerful magnetic field of aunular form and bas therehy concentrated the lines of force upon the nduced coil. He brings the whole coil within the influence
of the field. The effects are considerably magnified and the increased loudness is not accompanied by the usual loss
of articulation. Speech is said to be reproduced without any change of timbre. the magnetic effects of currents of electricity flowing around magiets or bars of soft iron.

The rapid and rbythmic magnetization and demagnetization of a bar of iron, or the increment and decrement of the magnetism of a magnet, will produce molecular disturbances, in its own mass tnd in the matter about it, that lead to the
oscillatory motions of the whole, which produce sonorous
vibrations that can be made manifest hy various devices, and particularly by that patented by Grabam Bell.
Other principles of electricity have also been utilized for For instance, Mr. Edison used the electro-chemical effect. The decomposition of a chemical solution in paper or on
chalk by the passage of currents through it produces a modification of the friction of two moving surfaces, which can sounding apparatus. I myself had the pleasure, in 1880 , of sounding apparatus. myself bad the pleasure, in 188 , of
electro-thermal effects of the current. The pased on the electro-thermal effects of the current. The passage of a cur-
rent through wires alwoys heats them and therefore produces expansion. If the wire be made fine enough, the
beat is generated and dissipated so rapidly, the expansion
and contraction are so quick, that sonorous vibrations are the result. Although I was ahle to speak through it very clearly, I bave not as yet developed this instrument into a practical form. Professor Dolbear bas recently utilized the simple than that of Bell. Two fiat circular disks of metal of ebonite. When one disk is electrified positively by a
charge of electricity, the other is electrified negatively by induction. These two opposite states produce attraction the result is that, when telephonic currents are transmitted,
we obtain sonorous vibrations, and consequently, the reproduction of speech.
Many other forms of telephone receivers bave been deMany other forms of telephone receivers bave been de-
vised and exhibited, in fact I bave recently seen quite a crop vised and exhibited, in fact I bave recently seen quite a crop
of them; but as they involve no new principle, and intro. duce no particular improvement, having been brought out
chiefly to try to avoid existing patents, I pass them over, and proceed to the next branch of my subject.
Our present patent law is, unfortunately, in so disorganized and chaotic a condition that evasion is of ten possible
and bence the questionable morality of doing a thing in

practically encouraged.
The possession of a patent is now no guarantee of property; it is granted without any discrimination, and cannot ture before a nou-technical and scientifically ipcompetent
tril,unal. We therefore cannot bope for any virtue in Eng lish inventors or security for real improvements until our
law is thoroughly revised. The question is before the House of Commons, and when woriy agitators bave fully ex-
bausted the patience of our legislators, we may hope for some attention to so real aud pressing a want.
Transmitters.-The great novelty and peculiarity of Bell's telephone was that the receiver and transmitter were similar
and reversible. Sonorous vibrations of air impinging on an iron disk caused it to vibrate in front of a magnet, around
one pole of which a portion of an electric circuit was wound. These vibrations of a magnetic substance in a wagnetic field produced currents of electricity in the coil of a distant station, there varied the magnetic strength of a distant station, there varied the magnetic strength of a
similar magnet so as to vary its at tractive force on a similar disk, by which it reproduced the motions of the first disk, ad thus, reproducing the sonorous vibrations of the air much energy was lost en route, and the effect sciurcely at-
tained a practical standard. Mr. Edison showed how to strengthen these currents. Taking advantage of a peculia resistance with the amount of pressure brought to bear upon to press upon a button of carbon, and so to vary the
strength of a current of electricity passing through it. This varying current. passing through the primary wire of au currents than the Bell instrument produced, and caused Professor Hugbes went a step further. He found a com bination of materials that were directly uffected by sonorous vibrations, which be called a "microphone," and be proved due to any influence of varying pressure on the mass of the a new fact. in nature, and be startled the scientific world by what the microscope bad already done for ninute objects. By the light thrown on the theory of the instrument by
Hughes, Edison's carbon transmitter bas been so improved by Blake, Hunnings, Moseley, Anders, and others, that
little apparently remains to be done. The telephone as a peaking instrument is now well-nigh perfect. $\mathrm{f}_{t}$ is quite possille to swear to a friend's voice at 100 miles distance ment under all circumstances is not due to any defects in the instrument itself, but to disturbing influences external to it, and consequent on its surroundings. The very perfec-
ion and sensitiveness of the apparat us itself are its chie enemies.
The true action of the microphone, or carbon-transmitter is very little understood; it introduces into a closed electric which, varying exactly with the sonorous vibrations imwhich, varying exactly with the sonorous vibrations im-
pinging upon it, causes the current to undulate in a way
exactly analogous to the varying souvd waves. This effect 